\title{
PLANTAS ORNAMENTALES DE LA CIUDAD DE TACNA
}

Rosario ZegarraZ. ${ }^{1}$

\author{
RESUMEN
}

Se describen 66 especies ornamentales, cultivadas en nuestra ciudad, correspondientes a 61 géneros y 38 familias consideradas las más comunes por su frecuencia. Se muestra el origen de ellas, algunas son nativas, otras en su mavoria introducidas. Varias de ella vistosas por sus hojas, la generalidad porsus inflorescencias. Elpresente trabajo constituye una guia para arquitectos, biólogos, ingenieros agrónomos, estudiantes y personas amantes de la jardinería que deseen conocer las especies ornamentales cultivadas en nuestra ciudad.

\section{INTRODUCCION}

Unjardín es una sinfonía de formas y colores, es un templo vivo consagrado a deleitar nuestro espíritu, contemplando la belleza incomparable de las flores. Las plantas que cultivamos en él simbolizan el homenaje que le rendimos a esos seres que mantienen nuestra vida.

Ciertamente que la característica más resaltante de las plantas es que pueden fabricar su propio alimento. Ningún animal puede hacer esto, siempre depende, para su alimentación, de otro animal o de las plantas. Estas, por el contrario, se abastecen por sí mismas, necesitando para ello sólo del suelo, el aire y la luz del sol.

Es por esto que las plantas son la base de vida en la tierra. Sin plantas no hay animales y no existiría tampoco el hombre.

Vemos que con el tiempo el modo de vida del hombre varió. Lo que en un principio fue necesidad pura y simple para procesar alimento, que llevó al desarrollo de la agricultura, se convirtió en deseo estético e intelectualmente sofisticado para rodearse de flores y de verdor, si bien la agricultura está destinada al cuerpo del hombre, las flores son el alimento del alma, del espíritu.

Durante muchos siglos el hombre tuvo que contentarse con las flores cortadas que sólo podian mantenerse un corto período de tiempo en el interior de

1. Doctora en biología la casa. Mientras tanto, dada la disponibilidad creciente de tierras, surgieron cada vez con mayor abundancia los jardines, unas veces grandes y suntuosos, otros pequeños y humildes, y por lo que ha llegado hasta nosotros, todos fueron fuentes de alegría para sus dueños, lo que constituía, aparte de su valor puramente estético, el fin último de su existencia.

Hoy en día, en cualquier casa, grande o pequeña, vieja o nueva, existe siempre un rincón con el que se puede situar una mancha de verdor y ello depende por completo de la voluntad y de la práctica de los que la habitan. En las grandes ciudades de la región costera, especialmente para aquellas que crecen aceleradamente, es un problema la insuficiencia de áreas verdes (parques, jardines) que tienen la función de purificar el aire, proporcionar recreo para la población y educar a la juventud, fomentando la cultura (jardines botánicos). Las áreas verdes, en las poblaciones costeras, son los pulmones de la ciudad.

\section{TRATAMIENTOSISTEMATICO}

\section{GIMNOSPERMAS}

\section{- FAMILIA PINACEAE}

\section{Pinus radiata D. Don ( $P$. insignis Dougl) "Pino"}

Arbol de copa amplia y redondeada. Acículas verde intenso de $10-15 \mathrm{cms}$. de longitud agrupadas en fascículos de 2 - 3. Con canales resiníferos. Especie monoica. Amentos masculinos terminales. Conos verticilados, ovoides, de color castaño. Semillas negruscas. Originaria de California. 
En diferentes plazas y avenidas de la ciudad. Casas particulares.

\section{- FAMILIA CUPRE SSACEAE}

\section{Cupressus macrocarpa Hartw. "Ciprés"}

Arbol de gran porte, copa piramidal, corteza gris oscuro. Follaje verde oscuro, hojas escamiformes, con olor a citronal. Amentos masculinos cortos terminales de color amarillo. Conos femeninos ovoides castaño claro, con 8-14 escamas ovulíferas, con 20 semillas cada uno. Nativa de California.

Es la especie más común de los cipreses, con ella se realizan numerosas figuras decorativas.

3. Cupressus sempervirens L. "Ciprés Italiano"

Planta arbórea angostamente piramidal. Corteza grisácea. Follaje verde oscuro, hojas escamiformes. Monoica. Amentos masculinos oblongos. Flores femeninas en conos o estróbilos ovoides castaños o grisáceos, con 8-14 escamas ovulíferas, con 8-20 semillas cada una.

Originaria del sur de Europa y el oeste asiático. Cultivada en parques y jardines. Se diferencia de la anterior por las ramas plegadas al tronco.

\section{- fAMILIA ARAUCARIACEAE}

4. Araucaria excelsa (Lamb.) R. Br., "Pino gigante"

Arbolde gran porte piramidal. Ramas verticiladas. Hojas escamiformes, curvas aovado-lanceoladas de $2 \mathrm{~mm}$. de ancho, de color verde. Flores agrupadas en amentos rojizos. Conos femeninos grandes, con escamas ovulíferas espiraladas, imbricadas. Semillas uniovuladas, cuneiformes. Originaria de Norfolk, al este de Australia - Nueva Zelandia y Nueva Caledonia.

Son los ejemplares de especies vegetales de mayor talla en nuestra ciudad. Observándose muy pocos de ellos, como en la avenida Bolognesi.

\section{ANGIOSPERMAS}

\section{A.DICOTILEDÓNEAS(Magnoliatae):}

\section{- fAMILIA CASUARINACEAE}

\section{Casuarina equisetifolia L. "Casuarina"}

Arbol de gran talla, copa piramidal, ramas estriadas, lleva 6-12 pequeñas hojitas escamosas en las articulaciones. Especie dioica. Amentos masculinos terminales. Flores femeninas reunidas en pseudo conos o estróbilos axilares. Fruto en sámara. Nativa de Australia.

Es una de las especies más cultivadas en la ciudad.

\section{- fAMILIA SALICACEAE}

6. Salix humboldtiana Willd. "Sauce criollo"

Arbol de gran porte, corteza rugosa. Hojas simples alternas lanceoladas, finamente crenado dentadas de $5-10 \mathrm{~cm}$, de largo, acuminadas.

Especie dioica. Amentos masculinos con estambres en número de cuatro protegidos por brácteas. Amentos femeninos con flores pistiladas aperiantadas. Fruto capsular Semillas diminutas lanosas. Originaria de América del Sur (Argentina). Poco cultivada.

\section{Populus nigra L. Itálica (Munch) Koehne "Alamo} Italiano"

Arbol con ramas laterales cortas, ascendentes, tronco rugoso. Hojas simples alternas deltoideas de $5-10 \mathrm{~cm}$. de largo, crenado dentadas, con pecíolo rojizo. Especie dioica. Amentos masculinos de 4-5 $\mathrm{cm}$. de largo. Amentosfemeninos más largos. Fruto capsular con semillas lanosas. Originaria del Viejo Mundo (Europa yoeste de Asia). Bastante frecuente en avenidas y plazas.

\section{- fAMILIA fAGACEAE}

\section{Quercus robur L. "Roble"}

Arbol de copa subglobosa, corteza rugosa. Especie caducifolia. Hojas pinnatilobadas, simples, alternas de $5-15 \mathrm{~cm}$. de largo. Monoica. Flores masculinas reunidas en amentos, aperiantadas. Flores femeninas agrupadas en espigas. Fruto en bellota, el aquenio protegido en su base por una cúpula con las brácteas fuertemente imbricadas.

Origen: Mediterráneo. Unico ejemplar existente en la avenida Bolognesi. Debe ser protegido.

\section{Quercus suber L. "Alcornoque"}

Arbol de copa irregular, perennifolia, corteza provista de una gruesa capa corchosa. Hojas simples alternas, coriáceas, aoyado oblongas de $3-7 \mathrm{~cm}$. de largo con borde dentado. Monoica. Amentos masculinos con numerosas flores estaminadas, con un perianto rudimentario de 4-7 tépalos. Las flores femeninas en corto número e involucradas. Fruto en bellota ovoide-oblonga, cuya cúpula presenta las escamas imbricadas. Originaria del Mediterráneo.

Los ejemplares existentes en la avenida Bolognesi deben ser protegidos. 
10. Quercus ilex L. "Encina"

Arbol de copa amplia, perennifolio. Hojas simples, polimorfas aovadas, enteras o espinoso-dentadas, con más de siete pares de nervaduras. Monoica. Flores masculinas agrupadas en amentos, numerosas. Flores femeninas reunidas en espigas en menor número. Bellota oblonga.Origen: Europa y Asia.

Ejemplares presentes en laalameda Bolognesi. Al igual que las especies anteriores deben de protegerse, por su escacez.

\section{- FAMILIA MORACEAE}

\section{Ficus elástica Roxb "CAUCHO"}

Arbol muy ramificado, de las ramas nacen raíces epígeas. Hojas simples alternas, oblongas, coriáceas, brillantes, verde oscuras en el haz d 10$30 \mathrm{~cm}$. de largo. Frutos en sicono elipsoidales amarillentos. Origen: India y Malaya.

Especie cultivada en parques, jardines de urbanizaciones.

\section{Ficus pandurata Sander "Caucho"}

Arbol de ramas gruesas. Hojas simples alternas coriáceas, panduriformes, verde oscuro de 20 $25 \mathrm{~cm}$. de largo, superficie arrugada entre los nervios secundarios. Siconos axilares, sésiles, globosos o subglobosos. Originaria de Africatropical.

Sele encuentra en jardines particulares, Plaza de Armas.

\section{Ficus benjamina L. "Cauchito"}

Arbolito, de hojas simples ovoides, verde oscuro. Algo estrechas y largas acuminadas, siconos de color amarillo. Antes se le cultivaba como planta de interior, hoy se le ve en varios parques, jardines, grifos, casas particulares.

\section{- FAMILIA PROTEACEAE}

\section{Grevillea robusta A. Cunn "Roble sedoso"}

Especie originaria de Austria. Arbol de gran porte, copa alargada. Perennifolia. Hojas simples alternas, bipinnatífidas, coriáceas de $15-25 \mathrm{~cm}$. de largo. Flores agrupadas en racimos, Flores tubulosas, pedunculadas de color anaranjado. Fruto en folículo. Florece en primavera y verano.

Se le observa en la avenida Bolognesi.

\section{- faMilia pHytolaccaceAe}

15. Phytolacca dioica L. "Ombú"
Especie bien desarrollada en la base. Copa globosa. Hojas simples alternas, oblongas o elípticas, enteras de $10-15 \mathrm{~cm}$. de largo. Dioica. Flores en racimos péndulos. Frutos carnosos verdosos compuestos de 6-14 carpelos verticilados. Semillas negras.

Oriunda de Sudamérica, árbol típico de Argentina, junto con el Ceibo. Existen pocos ejemplares en nuestra ciudad, a los cuales hay que cuidarlos. En avenida Bolognesi.

\section{- FAMILIA CHENOPODIACEAE}

16. Kochia ocoparia var. tricophylla Hort. "Pinito chino"

Especie anual, herbácea o subleñosa en la base. Hojas lineares de 5-9 cm. de largo. Flores amarillentas dispuestas en pseudo paojas piramidales. Fruto lenticular rodeado porlos sépalos.

Hermosa especie ornamental por su follaje. Es bastante cultivada.

\section{FAMILIA NYCTAGINACEAE}

\section{Bouganvillea spectabilis Willd "Buganvilla"}

Arbusto espinoso, generalmente apoyante. Espinas de $2.5-5 \mathrm{~cm}$. de largo. Hojas simples ovoides, enteras de $5-7.5 \mathrm{~cm}$. de largo. Flores blancas tubulosas, protegidas por brácteas o hipsófilos en número de tres, de colores llamativos púrpura, rosado, rojo-ladrillo, amarillo, blanco, etc. Fruto anguloso, rodeado por el tubo de perianto. Originaria de Brasil.

Es la especie representativa de la ciudad, sobre todo en la Procesión de la Bandera. Cultivada en toda la ciudad.

\section{Mirabilis jalapa L. "Don Diego de noche"}

Especie arbustiva de 0.5-1 $\mathrm{m}$. de altura, ramificada. Hojas simples opuestas aovadas de 6 $12 \mathrm{~cm}$. de largo. Flores solitarias axilares de colores llamativos blanco, rojo, amarillas a menudojaspeadas infundibiliformes. Antocarpio leñoso, rugoso. Semilla harinosa. Nativa de América.

Se cultiva en casas particulares, jardines de urbanizaciones, pasaje Vigil.

\section{- fAMILIA AIzOACEAE}

19. Mesembryanthemum roseum Willd. (Lampranthus roseus (Willd.) Schwant) "Rayito de sol"

Planta perenne, de ramas extendidas. Hojas 
falcadas de $2.5-3.5 \mathrm{~cm}$. de largo. Flores solitarias o de a tres, rosado oscuras, con numerosos pétalos, estambres igualmente numerosos. Fruto capsular. Nativa de Sudáfrica.

Ampliamente cultivada en todos los jardines de la ciudad.

\section{FAMILIA MAGNOLIACEAE}

\section{Magnolia grandiflora L. "Magnolia"}

Arbol de gran porte, caducifolio. Hojas simples, alternas, conriáceas, haz brillante, pubescente en el envés, de $10-20 \mathrm{~cm}$. de largo. Hermosas flores solitarias axilares. Con 9 pétalos blancos perfumados. Numerosos estambres. Fruto conformado por varios folículos. Nativa de América Boreal.

Hermosa especie, muy pocos ejemplares de ella se encuentran en la ciudad, tal vez sólo tres, uno de ellos en el local central de nuestra universidad.

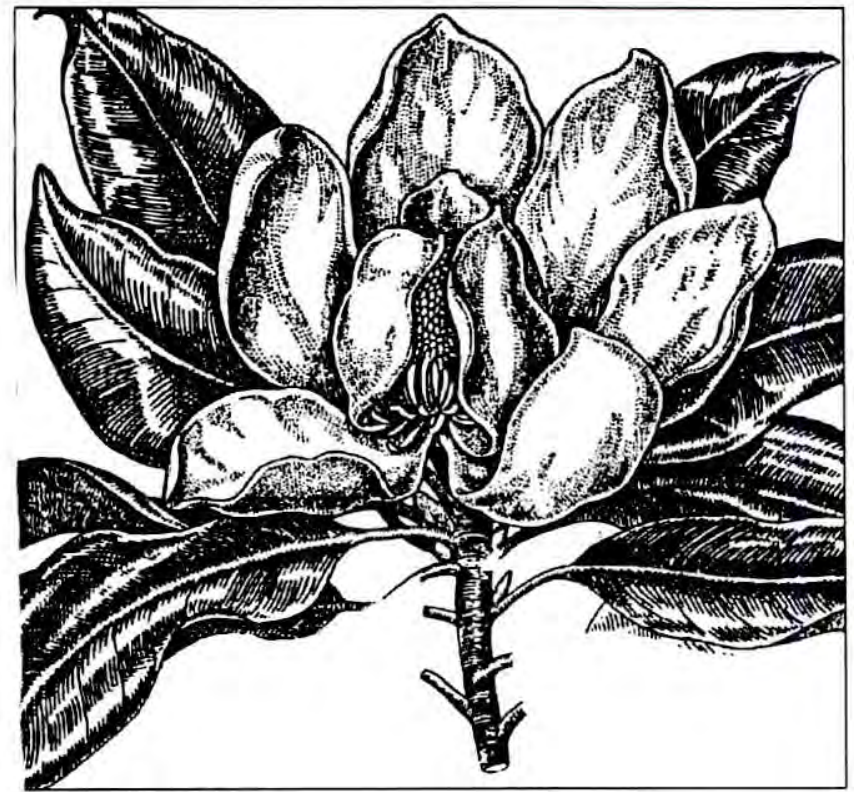

\section{- fAMILIA CRASSULACEAE}

21. Crassula arborescens (Mill.) Willd. "Rosa verde"

Especie arbustiva, ramificada. Hojas simples redondeado-obovadas, espatuladas obtusas, enteras, suculentas de $3.5-7.5 \mathrm{~cm}$. de largo. Inflorescencia cimosa. Flores blancas pentámeras. Fruto en folículo. Originaria de Sudáfrica.

Frecuente observarla en jardines particulares, de urbanizaciones.

\section{FAMILIA ROSACEAE}

\section{Rosa L. "Rosa"}

Este género tiene más de 100 especies originarias de las regiones templadas y subtropicales del hemisferio norte.

Arbustos erguidos, sarmentosos o trepadores, conaguijones. Hojas compuestas, imparipinnadas, provistas en labase de dos estípulas. Flores solitarias o agrupadas en inflorescencias terminales. Pétalos 5 , o numerosos en las variedades de flores dobles o semidobles. El color de los pétalos es variado: Blanco, amarillo, rosado, rojizo, púrpuras etc. Estambres y pistilos numerosos. Fruto compuesto por numerosos aquenios, constituyendo un cinorrodon.

Las especies de éste género son las más cultivadas tanto en jardines particulares, asi como en parques, alamedas de la ciudad.

\section{- FAMILIA LEGUMINOSAE (FABACEAE)}

\section{Acacia melanoxylon L. Brown "Acacia" "Mimosa"}

Arbol de tronco grueso, copa cónica o globosa. Perennifolia. Follaje persistente, denso. Filodios lanceolados de $5-11 \mathrm{~cm}$. de longitud. Inflorescencia en capítulos globosos. Flores tubulosas de color amarillo. Fruto en lomento. Semillas negras. Nativa del sudeste de Australia y Tasmania.

Cultivada en los parques y avenidas de la ciudad.

\section{Piptadenia grata (Willd.) "Vilca"}

Especie arbórea, de copa extendida, inerme de gran porte. Hojas compuestas, grandes bipinnadas con 9 - 11 pares de pinas, foliolos numerosos. Caítulos redondos sobre pedúnculos de $2.5-3 \mathrm{~cm}$. de longitud. Flores pequeñas, pétalos amarillos, estambres exertos. Fruto en legumbre comprimida, coriácea, seca. Nativa de América del Sur.

Especie cultivada en toda la ciudad, proporciona bastante sombra.

25. Caesalpinia gilliesii (Hook) Benth. "Ba'rbas de chivo"

Arbusto glanduloso. Hojas compuestas de 10$16 \mathrm{~cm}$. de longitud, pinas 7 - 14 yugas cada una con $6-10$ pares de foliolos. Inflorescencia en racimo. Flores con pétalos tenues, amarillo claro, estambres y estilos exertos de color rojo. Fruto en legumbre comprimida, seca. Oriunda de América del Sur (Argentina). 
Bello arbusto de adorno, cultivado en la ciudad con regularfrecuencia.

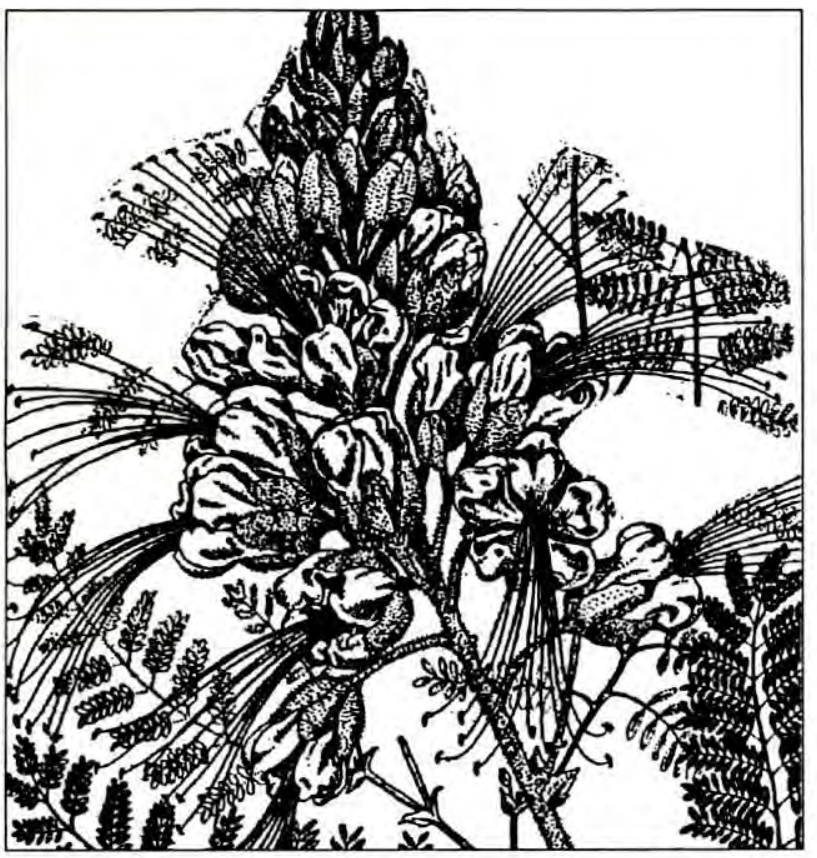

26. Parkinsonia aculeata L. "Parkinsonia" "Paloverde"

Arbol de copa ancha. Tronco y ramas de color verde. Hojas compuestas con estipulas espinosas con 1 - 3 pares de pinas de $15-30 \mathrm{~cm}$. de longitud. Folíolos distanciados. Flores agrupadas en racimos. Corola con los pétalos de color amarillo, el superior interno con manchas rojas, Legumbres o vainas con 1 - 15 semillas. Nativa de América.

Se le encuentra en todos los parques, avenidas, jardines de urbanizaciones.

\section{Tipuana tipu (Benth) OK "Tipa"}

Arbol originario de Argentina, Bolivia. Copa redonda. Caducifolio. Hojas compuestas con 6 - 11 pares de folíolos. Flores reunidas en racimos. Corola papilionácea, con pétalos amarillo anaranjado, con estrías rojas en el estandarte. Fruto en sámara.

Especie cultivada en la Plaza Zela, Plaza de Armas, UNJBG, Centros Educativos, etc.

28. Robinia pseudoacacia L. "Acacia blanca" "Arbol de las Pagodas" "Falsa Acacia"

Arbol caducifolio de corteza gris. Ramas con grandes estípulas espinosas. Hojas compuestas imparipinnadas con 3-14 pares de folíolos elípticos. Racimos axilares péndulos. Flores con corola papilionácea blanca fraganciosas y nectaríferas.
Fruto con una legumbre de color marrón. Semillas pequeñas reniformes.

Origen: Norteamérica. Existen pocos ejemplares en la avenida Bolognesi, avenida Grau. Debe ser protegida.

\section{Erythrina cristagalli L. "Ceibo"}

Arbol pequeño de corteza rugosa. Hojas trifoliadas. Racimos con numerosas flores papilionáceas de color rojo. Fruto en legumbre subcilindrica, semilunar. Semillas.

Nativo de América del Sur (Argentina, Uruguay y sur de Brasil).

Arbol típico de Argentina. Existen pocos ejemplares. Plaza Vigil, avenida Bolognesi, casas particulares.

\section{- fAMILIA OXALIDACEAE}

\section{Oxalis hedysaroides rubra "Acedera"}

Especie arbustiva y erguida, con tallos delgados, Hojas compuestas trifoliadas, Folíolos ovalado-acuminados, de color rojo intenso. Inflorescencia cimosa con flores amarillas. Fruto capsular.

Especie oriunda de América del Sur (Colombia, Ecuador y Venezuela). Muy poco cultivada. Se le encuentra en la avenida Bolognesi.

\section{- FAMILIA gERANIACEAE}

\section{Pelargonium zonale (L.) Ait "Geranio"}

Subarbustiva. Hojas simples alternas, festoneadas florescencia en umbela simple. Las flores provistas de un espolón soldado al pedicelo. Pétalos de colores variados: blanco, rojo, rosado etc. Fruto capsular. Oriunda del sur Africa.

Especie muy cultivada en la ciudad, por su rusticidad.

Existen otras especies muy poco cultivadas como Pelargonium peltatum "Geranio hiedra", llamado asi por el parecido de sus hojas con las de la hiedra.

\section{- fAMILIA mELIACEAE}

\section{Cedrela odorata L. "Cedro"}

Arbol de gran altura. Tronco recto de madera rojiza. Hojas grandes compuestas de color verde intenso. Más de 10 foliolos. Flores de color verde amarillento y aromáticas. Fruto capsular. Nativa de Antillas y Trinidad y Tobago. Poco frecuente en la ciudad. 


\section{- FAMILIAEUPHORBIACEAE}

33. Euphorbia pulcherrima Willd "Corona del Inca" "Florde Navidad".

Especie arbustiva, laticifera. Hojas simples alternas. Flores reunidas en ciatos, con una flor femenina central y varias masculinas reducidas a un solo estambre articulado. Estas flores declinomonoicas están protegidas por brácteas o hipsófilos de colores llamativos: rojo, amarillo o anaranjado, dando la impresión de ser éstas las flores. Fruto capsular. Originaria de México.

Es una de las especies más cultivadas en la ciudad.

\section{Codiaem variegatum (L.) Blume "Croton"}

Arbusto de hojas simples, alternas coriáceas, de forma y color variado. Inflorescencia en espiga larga, flores pequeñas y poco llamativas. Con innumerables formas hortícolas.

Nativa del sur de la India, Ceilán a través del Himalaya hasta las Islas Sunday. Pequeños arbustos cultivados en diferentes parques y casas particulares.

\section{Acalypha Willkesiana Muell. Arg. "Califa"}

Planta arbustiva, frondosa, de tallos cortos. Hojas ovoides-acuminadas, con borde serrado o crenado ybordeado por una franja amarilla o blanco crema. Esta es esencialmente una planta de follaje. Las flores son poco llamativas de color amarillo verdoso. Originaria de Nueva Guinea. En parques, jardines de casas particulares, etc.

\section{- FAMILIA ANACARDIACEAE}

\section{Schinus mollle L. "Molle"}

Arbol resinoso de $2-3.5 \mathrm{~m}$. de altura. Tronco con corteza marrón oscura o grisácea. Hojas compuestas imparipinnadas, color verde claro. Folíolos alternos en número de $6-15$ pares. Racimos compuestos sobre ramas terminales. Flores pequeñas, corola blanco-rosada o blanco-amarillenta. Fruto drupáceo de color rosado intenso.

Nativo de América tropical (Ecuador, Perú y Bolivia).

Se encuentra en avenida Bolognesi, frente al parque Las Américas, avenida Grau.

\section{- FAMILIA SAPINDACEAE}

37. Sapindus saponaria L. "Chololo" " Choloque".
Arbol. Hojas compuestas imparipinnadas, con el raquis alado, de $15-20 \mathrm{~cm}$. de largo. Flores pequeñas blanco-verdosas reunidas en racimos compuestos. Fruto drupáceo rico en saponinas, con una semilla de color negro. Originario de América tropical y subtropical. En casas particulares. Plaza de Armas.

\section{- FAMILIA MALVACEAE}

\section{Hibiscus rosa-sinensis L. "Cucarda".}

Arbustiva. Hojas simples, alternas ovoides o cordiformes, acuminadas, de margen dentado, haz brillante. Flores solitarias axilares de color blanco, rosado, anaranjado, amarillo, rojo. Con numerosos híbridos. Nativa de China y Japón. Cultivada en toda la ciudad.

\section{- FAMILIA BOMBACACEAE}

39. Chorisia speciosa "Ceibo" o "Palo borracho"

Arbol vistoso, con el tronco provisto de espinas. Hojas simples pecioladas, alternas, digitadas. Flores vistosas de color rosado. Fruto capsular. Semillas con pelos sedosos. Originario de Sudamérica cálida.

Existen pocos ejemplares de este belloárbol en casas particulares de la ciudad.

\section{- FAMILIA PUNICACEAE}

40. Punica granatum L. "Granado"

Pequeño arbolito. Hojas simples lanceoladas, opuestas, sin estípulas. Flores solitarias. Cáliz carnoso. Corola con pétalos frágiles rojos. Estambres numerosos. Fruto en balausta. Semillas envueltas por un arilo ácido o azucarado de color rosado. Especie nativa de Europa y Asia.

Es la especie que figura en el escudo de nuestra ciudad.

\section{- FAMILIA MIRTACEAE}

\section{Eucaliptus globulus Labill "Eucalipto"}

Arbol gigante, de follaje magnífico. Hojas jóvenes sésiles, anchas, opuestas, cordiformes y acuminadas, glaucas. Hojas adultas alternas, pecioladas, falcadas. Flores axilares, al estado de botón recubiertas por un opérculo caduco. Fruto con numerosas semillas. Especie de origen australiano.

Poco frecuente en los parques de la ciudad, se observa en colegios, UNJBG. 
- fAMILIA ARALIACEAE

\section{Hedera helix L "Hiedra"}

Arbusto trepador mediante raices adventicias situadas en el tallo. Hojas simples, alternas, lobuladas verde brillantes en el haz, coriáceas. Flores poco aparentes, reunidas en umbelas simples. Fruto en baya de color negro. Especie cosmopolita.

Se le encuentra en diferentes parques de la ciudad, parte posterior de la Catedral, trepando en las palmeras datileras de la Plaza de Armas.

\section{- fAMILIA PLUMBAGINACEAE}

\section{Plumbago capensis Thumb. "Jazmin Azul"}

Arbusto. Hojas simples pinnatífidas, envés cubierto por escamas blanquecinas. Flores reunidas en corimbos. Cáliz glanduloso. Corola hipocrateriforme, pétalos de colorceleste. Androceo cinco. Ovario súpero. Fruto capsular.De origen sudafricano.

Ideal para muros, cercos, pérgolas. Cultivada en el pasaje Vigil, casas particulares.

\section{- FAMILIA APOCYNACEAE}

44. Nerium oleander L. "Laurel rosa" "

Arbusto laticifero venenoso. Hojas simples, lanceoladas, coriáceas, verticiladas. Inflorescencia cimosa. Flores simples o dobles. Pétalos de color blanco o rosado. Fruto capsular. Originario del Mediterráneo oriental.

Presente en todos los jardines de la ciudad.

45. Catharanthus roseus L. "Isabelita"

Arbusto pequeño. Hojas simples oblongas, verde oscuras, margen entero, brillantes en el haz. Flores solitarias axilares, corola hipocrateriforme, pétalos blancos o rosados. Fruto capsular. Nativo de Madagascar.

Cultivada en jardines particulares.

\section{Plumeria alba L. "Suche"}

Arbol laticifero. Hojas simples alternas, margen entero. Flores grandes vistosas fraganciosas agrupadas en racimos. Corola gamopétala pentalobulada. Frutocapsular. Originario de América.

Pocofrecuente.

\section{- familia oleaceAE}

47. Ligustrum vulgare L. "Ligustro"
Arbol. Hojas simples opuestas. Flores agrupadas en racimos compuestos, tetrámeras de prefloración valvada. Corola de color blanco. Fruto drupáceo de color negro. Nativa de Europa y norte del Africa.

Poco frecuente, cultivada en la avenida Bolognesi, jardines de urbanizaciones

48. Jasminum grandiflorum L. "Jazmín"

Especie arbustiva, con tallos largos y delgados. Hojas compuestas, con cuatro pares de folíolos creciendo en pares desde un eje central. Inflorescencia cimosa Flores blancas, a veces rosadas porfuera, con prefloración imbricada, corola hipocrateriforme. Fruto lobulado. Originaria de la región del Himalaya en la India.

Especie cultivada en casas particulares.

49. Fraxinus americana L. "Fresno"

Arbol. Hojas compuestas imparipinnadas, constituidas por cuatro pares de folíolos. Las hojas miden $20-30 \mathrm{~cm}$. de largo. Flores unisexuales. Fruto en sámara. Nativa de Norteamérica.

Es bastante común en la ciudad. Parque de las Américas, avenida Leguia, UNJBG.

\section{- faMilia loganiaceAE}

50. Buddleja globosa Hope "Quishuar matico" "Paguhin"

Arbol pequeño. Hojas simples, opuestas lanceoladas a aovado lanceoladas, pubescentes en el envés. Flores tetrámeras amarillas pequeñas agrupadas en capitulos redondeados largamente pedunculados en el ápice de las ramas. Originaria de Perú y Chile.

Poco frecuente. Cultivada en algunos parques de la ciudad.

\section{- fAMILIA VERBENACEAE}

\section{Lantana camara L. "Lantana"}

Planta arbustiva o semileñosa. Hojas simples, opuestas, ovoides, dentadas, ásperas y arrugadas con envés tomentoso. Inflorescencia en capítulo. Flores pequeñas numerosas, de color amarillo, rosado, rosa o naranja. Las flores se abren sucesivamente hacia el centro. Fruto drupáceo de color negro. Oriunda de Antillas, México y Texas.

Utilizada para cerco vivo, en diferentes parques de urbanizaciones, UNJBG. 
- FAMILIA MIOPORACEAE

\section{Myoporum serratum "Mioporo"}

Arbol de copa redonda. Hojas simples, alternas, borde aserrado. El paréquima foliar presenta unas pequeñas glándulas oleiferas. Flores pequeñas axilares, solitarias o fasciculadas, pentámeras. Corola blanca con manchas granates. Fruto drupáceo de color rosado oscuro. Nativa de Australia.

Muy frecuente en los parques de la ciudad; avenida Leguía, avenida Bolognesi, UNJBG.

\section{- faMilia solanACEAE}

\section{Brugmansia candida (Persoon) Salford "Floripondio"}

Especie arbórea pequeña. Tallo con ramas péndulas. Hojas simples, alternas, aovado lanceoladas, oblongas y aovadas, asimétricas, pubescentes. Flores axilares solitarias. Cáliz espatulado, tubuloso. Corola infundibiliforme, pétalos blancos. Androceo \%. Fruto capsular. Especie nativa de América.

Frecuente en los jardines de la ciudad.

\section{- FAMILIA BIGNONIACEAE}

54. Spathodea campanulata Beaur. "Tulipán africano"

Arbol caducifolio, vistoso de grandes hojas compuestas imparipinnadas. Flores agrupadas en racimos, zigomorfas, de color rojo escarlata. Estambres didinamos. Fruto capsular. Semillas aladas.

Hermoso árbol cultivado en la mayoría de los parques y jardines de la ciudad. De origen africano.

55. Jacarandá acutifolia Humb et. Bonpl.

Arbol de varios metros de altura. Grandes hojas bipinnadas. Inflorescencia racimosa, con flores zigomorfas de color violáceo. Fruto capsular. Con semillas aladas. Nativa de Brasil.

Cultivada en avenida Bolognesi, avenida Grau, avenida Leguía, casas particulares.

56. Pyrostegia venusta (Ker-Gawl.) Miers. "Lluvia de oro"

Enredadera leñosa. Follaje persistente. Hojas compuestas. Dos o tres folíolos aovados de 4 - 8 $\mathrm{cm}$. de largo, a menudo con un zarcillo en el extremo. Flores tubulosas, zigomorfas, pétalos anaranjados reunidas en racimos. Fruto capsular.

Cultivada en jardines de casas particulares.
57. Tecoma stans (L.) Juss. "Tecoma" "Huaranhua"

Especie arbórea. Tronco ramificado, corteza gris claro. Hojas compuestas imparipinnadas. Inflorescecia racimosa con flores zigomorfas, llamativas, de color amarillo intenso. Fruto capsular. Semillas planas, rodeadas por una membrana más o menos ancha, la cual facilita la diseminación. Nativa de América tropical (Perú).

Frecuente en parques y jardines.

\section{- FAMILIA CAPRIFOLIACEAE}

\section{Lonicera japonica Thunb. "Madreselva"}

Especie arbustiva, ramas volubles. Hojas simples oblongas, opuestas. Flores axilares. Corola bilabiada, con pétalos amarillos y blancos. Fruto en baya. Originaria de China y Japón.

Cultivada en casas particulares.

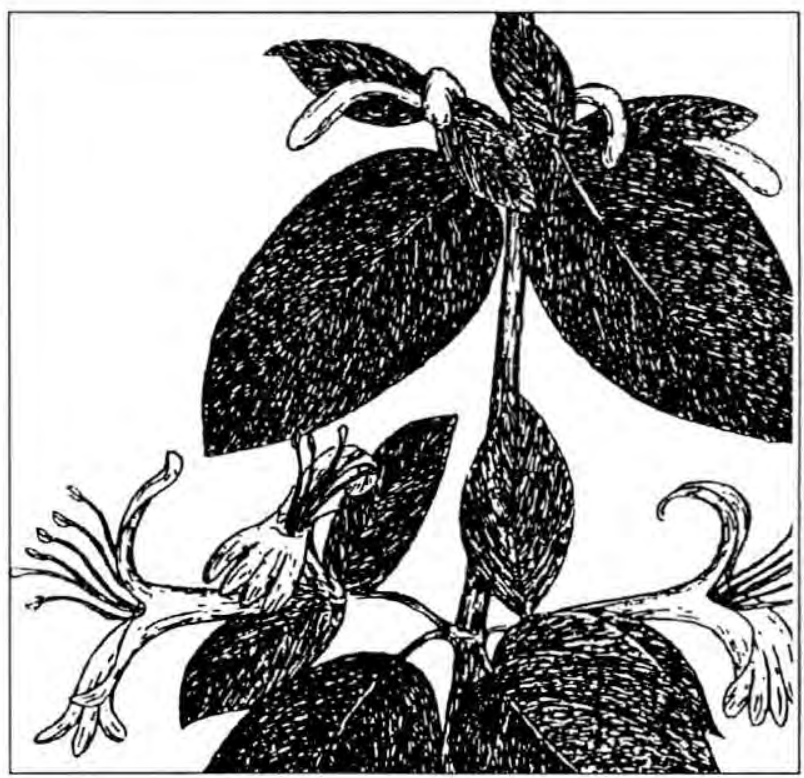

59. Sambucus nigra "Saúco europeo"

Especie arbustiva. Hojas compuestas imparipinnadas, de $15-20 \mathrm{~cm}$. de largo. Inflorescencia cimosa multipara, con un gran numero de flores actinomorfas, de pétalos blancos. Fruto drupaceo. Nativa de Europa.

Poco frecuente en parques y jardines de la ciudad.

\section{- fAMILIA COMPOSITAE (ASTERACEAE)}

60. Helianthus annuus L. "Girasol"

Herbácea. Pubescente. Hojas simples, alter- 
nas, ligeramente cordiformes, margen aserrado. Capítulos heterógamos, flores liguladas amarillas, las centrales tubulosas amarillas. Fruto en cipsela. Oriunda de América del Norte.

Frecuente en los jardines de la ciudad.

61. Chrysanthemum maximum "Manzanillón"

Especie herbácea. Hojas simples ligeramente espatuladas. Capítulos heterógamos. Flores periféricas liguladas de color blanco. Flores centrales tubulosas amarillas. Fruto en aquenio. Nativa de Europa (España).

Cultivada con bastante frecuencia en los jardines de la ciudad.

62. Cineraria maritima (Senecio cineraria) "Cineraria"

Plantaherbácea. Hojas simples pinnatipartidassectas, alternas, pubescentes de color plomo. Capítulos heterógamos. Flores liguladas ytubulosas de color amarillo. Fruto aquenio. Originaria del Mediterráneo.

Cultivada para bordes en parques de la ciudad.

B. MONOCOTILEDONEAS(Liliatae):

- fAMILIA PALMAE (ARECACEAE)

63. Washingtonia filifera (Lindeu) H. Wendl "Palmera de abanico"

Palmera de gran tamaño, alcanzando varios ms. de altura, de estípite cilíndrico, cubierto por las cicatrices foliares. Hojas en forma de abanico, con segmentos flexibles provistos de hilos o filamentos. Peciolo 1-2ms. de largo con espinas curvas en toda su longitud. Espádices ramificados protegidos por una espeata basal. Frutos drupáceos negruzcos. Nativa de América boreal.

Frecuente en toda la ciudad.

64. Phoenix canariensis Hort. "Palmera datilera"

Palmera de estípite robusto, cubierto por cicatrices foliáceas, de $10-20 \mathrm{mts}$. de altura. Hojas pinnadas. Espádoces erguidos o péndulos interfoliáceos, más pequeños que las hojas. Fruto en drupa de color amarillo-anaranjado.

Origen: Islas Canarias. avenida Bolognesi, avenida Grau. Se le cultiva en toda la ciudad.

\section{- fAMILIA LILIACEAE}

65. Aloe vera $L$. "Zábila"

Especie perenne. Hojas suculentas, de borde dentado. Escapo floral que lleva a la inflorescencia en racimo. Flores tubulosas, de tépalos amarillo anaranjados. Fruto capsular. Originaria del Mediterráneo.

Especie frecuente en casi todos los hogares de la ciudad.

\section{- fAMILIA CANNACEAE}

66. Canna índica L. "Achira"

Especie herbácea, caulescente rizomatosa. Hojas elipticas o aovado-lanceoladas Flores asimétricas, reunidas en cima helicoidal. Tépalos actinomorfos, estambres asimétricos. Ovario infero. Fruto capsular. Semillas esféricas negras. Nativa de América tropical

Frecuente en los jardines de la ciudad.

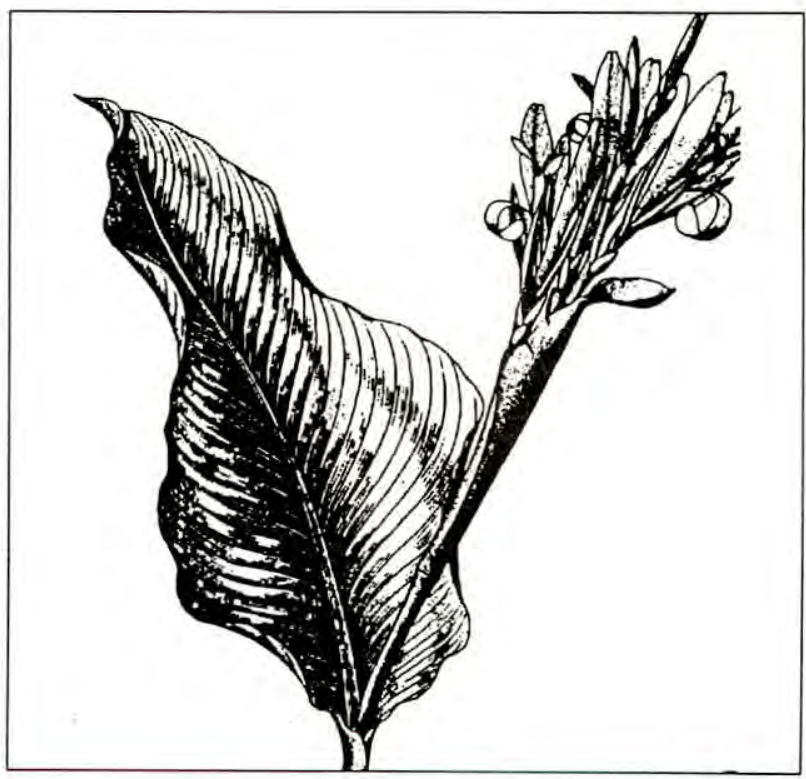

\section{BIBLIOGRAFIA}

Kramer Jack (1981). Flowering Houseplantas. Salamander Book.London.

Strasburger E. y otros (1986). Tratado de Botánica. Ed.Marín.S.A.España
Zegarra R. (1994). La vegetación desértica perenne de Tacna: Estudio biosistemático y sus recursos naturales. Revista Nueva Imagen Nro. 5 UNJBG Tacna-Perú. 